\title{
Malformations reported in chorionic villus sampling exposed children: A review and analytic synthesis of the literature
}

Joan M. Stoler, $M D^{1}$, Caroline K. McGuirk, $M S^{1}$, Ellice Lieberman, $M D, D r P H^{2}$, Louise Ryan, $P h D^{3}$, and Lewis B. Holmes, $M D^{1}$

\begin{abstract}
Purpose: To determine whether the frequency of vascular disruption defects, other than limb defects, is increased in reports of chorionic villus sampling (CVS) exposed children compared with an unexposed population. Methods: Only studies that reported the total number of CVS-xposed pregnancies and details of pregnancy outcome, including all the malformations, were included. Twenty-five articles met these criteria. Results: The frequencies of gastroschisis, intestinal atresias, and clubfoot were significantly increased among the CVS-exposed infants as compared with the baseline unexposed population. The frequencies of other vascular disruption defects, including Poland sequence, amniotic band sequence, and cleft lip/cleft palate, were not increased. Conclusion: CVSexposed children have an increased frequency of intestinal atresia, gastroschisis, and clubfoot compared with the nonexposed population. The fact that an increased frequency of other defects attributed to vascular disruption was not found may be due to under-ascertainment, misclassification, or "lumping" of the defects identified in previous studies. Genetics in Medicine, 1999:1(7):315-322.
\end{abstract}

Key Words: Chorionic villus sampling, vascular disruption, gastroschisis, intestinal atresia

Several studies have suggested that the limb defects reported in chorionic villus sampling (CVS) exposed children may result from vascular disruption. ${ }^{1,2}$ Support for this proposed mechanism comes from vascular anomalies, such as aberrant vessels, ${ }^{3}$ and evidence of emboli in the fetal vasculature or placenta, ${ }^{4}$ reported in similar defects in nonexposed children. Other malformations hypothesized to be secondary to vascular disruption include: gastroschisis, ${ }^{5}$ intestinal atresias, ${ }^{6}$ hemifacial microsomia, ${ }^{7}$ Poland sequence, ${ }^{8}$ Klippel-Feil anomaly, ${ }^{8}$ Moebius sequence and oromandibular-limb hypogenesis (OMLH) sequence, ${ }^{8,9}$ horse-shoe kidneys, unilateral renal agenesis, unilateral urethral obstruction sequence, ${ }^{10}$ porencephaly, ${ }^{11}$ and talipes equinovarus. ${ }^{10}$ Many of these defects in monozygotic twins have been reported to have had vascular etiologies. ${ }^{12}$ Intestinal atresias have been associated with two exposures thought to cause vascular disruption, maternal cocaine abuse ${ }^{13}$ and intra-amniotic injections of methylene blue. ${ }^{14}$ Similarly it is hypothesized that premature ablation or occlusion of the omphalomesenteric artery results in gastroschisis. $^{5}$

From the 'Genetics and Teratology Unit, Pediatric Service, Massachusetts General Hospital and Harvard Medical School; the 'Department of Obstetrics and Gynecology' Brigham and Women's Hospital and Harvard Medical School; and the 'Division of Biostatistics, Dana Farber Cancer Institute and Harvard School of Public Health. Boston Massachusetts.

Dr. Joan M. Stoler, Genetics and Teratology Unit, Massachusetts General Hospital, 55 Fruit Street, Warren 801, Boston, MA 02114.

Received: September 7, 1999

Accepted: November 18, 1999.
If the basis of the limb defects reported in CVS-exposed children is vascular in origin, one would expect to see a similar increase in other defects caused by the same mechanism. We have reviewed the published literature on CVS-associated malformations to determine whether there is an increased frequency of defects associated with vascular disruption in comparison with the frequency in an unexposed population of newborn infants.

\section{MATERIALS AND METHODS}

We sought to identify all articles published in the English literature from 1987 to 1997 on CVS in which malformations were reported. These articles were identified from multiple sources: databases, reference lists, review of abstracts, and recommendations of investigators in the field. The databases searched were MEDLINE, EMBASE, Biosis Serial Sources, Conference Papers Index, Inside Conferences, Dissertation Abstracts Online, Current Contents/Life Sciences, and the Cochrane Library. The search was conducted using the keyword/ phrase 'chorionic villus sampling' or 'chorionic villus biopsy' along with other spellings (chorionic villous sampling, chorionic villi sampling, chorion villus sampling, chorion villous sampling, chorion villi sampling, and CVS). The references listed at the end of the articles that were obtained were reviewed for additional references. All of the abstracts from meetings published in the American Journal of Human Genetics, American Journal of Obstetrics and Gynecology, and Teratology were reviewed for additional citations. The list of the 
compiled articles was reviewed by members of the CVS Birth Defects Registry Advisory Committee and participants of the 1992 NICHD Workshop on CVS and Limb and Other Defects ${ }^{15}$ who added additional references.

In all, 92 published articles were identified and analyzed for description of any malformations identified in CVS-exposed fetuses (both liveborns and abortuses). Table 1 describes the range of birth defects reported.

To determine the frequency of specific defects among CVSexposed infants, the subset of articles providing sufficient information to permit calculation of rates were reviewed. Articles were included in this analysis only if the following were present:

1. The total number of women who had the CVS procedure in the series;

2. descriptions of nonlimb malformations; and

3. documentation of pregnancy outcome (abortion, stillbirth, and liveborn).

Articles were excluded for the following reasons:

1. Case reports;

2. case-control studies;

3. reviews;

4. did not report the total number of women who underwent CVS in their population;

5. descriptions of the malformations were inadequate (i.e., listed solely the total number of malformations or type of malformation, such as gastrointestinal malformation without the specific details); and

6. registry data in which the data collection relied on voluntary reporting of the malformations (as under-reporting of malformations is a problem with such methods of data collection).

If multiple articles included the same cases, only the most recent article was used in the compilation. For example, for articles written by the same group of authors, the time frame during which the cases were included was examined carefully to make sure that there was no overlap.

Twenty-five publications from 1987-1997 met the inclusion criteria. ${ }^{16-40}$ All of these studies included more than 100 patients who underwent CVS. Malformations due to single gene defects, such as achondroplasia, Apert syndrome, short rib polydactyly syndrome, and those due to chromosome defects (such as trisomies, duplications, and deletions), and recognized malformation syndromes (other than vascular disruption syndromes) were excluded in calculating the rates of malformations. Information on defects seen in abortuses were included, if a detailed description of the defects in the abortuses was provided. In many articles, the details about the cases that were terminated due to a fetal defect were not given, only noting that the fetal defect was present. Only eight papers ${ }^{17,19,21,23,25,32,37,39}$ detailed the structural malformations in the terminations with some being confirmed by autopsy, others only by prenatal ultrasonography, all of which were included in our calculations. Most of these cases included major defects such as neural tube defects, renal agenesis, and body stalk anomaly.

The transcervical method only was used in eight studies, $16,17,22,23,28,29,31,39$ the transabdominal method only in eight studies, $18.19,21,24,30,32.33,36$ whereas both methods were used in six studies. $20,25,34,37,38,40$ Three studies did not report the method employed. ${ }^{26,27,35}$ The timing of the CVS across studies varied widely. Seven studies included procedures performed before 9 weeks. ${ }^{18,19,22,25,27,30,38}$ Four studies did not report the timing of the CVS procedures. ${ }^{26,28,34,35}$

The baseline data for the prevalence of each defect in nonexposed infants and fetuses were derived from two sources: ${ }^{1}$ the Brigham and Women's Hospital (BWH) Active Malformation Surveillance Program and ${ }^{2}$ published prevalence data. ${ }^{41-42}$ The BWH Active Malformation Surveillance Program, which is on-going, has collected data from 161,252 livebirths and abortuses at this hospital for the years 1972-1974 and 19791994, the sample used for the comparison. Index cases are identified from a daily review of the medical records of all newborn infants and other reports, such as autopsies and diagnostic studies ${ }^{43}$ Interviews with the mothers and the review of the mother's medical record confirmed that she did not undergo CVS during that pregnancy. Infants whose mothers had planned to deliver elsewhere, but were transferred to the BWH after the prenatal detection of a fetal abnormality or because of a complication of pregnancy, were excluded from the analysis. In addition, infants whose malformations were part of a recognized malformation syndrome (other than vascular disruption syndromes), genetic disorder, associated with a chromosome abnormality or were associated with a recognized teratogen were excluded. Published prevalence data were used for all of the defects other than the terminal transverse limb defects with nubbins. Published prevalence data for limb defects did not separate out those terminal transverse limb defects with nubbins.

The frequency of the defects in the CVS-exposed population attributed to vascular disruption was calculated by dividing the number of cases with the defect in question by the total number of CVS-exposed babies in all of the studies. The frequency of several defects not thought to be secondary to vascular disruption were also calculated for comparison.

Analysis was performed using a Poisson random effects model, as described by Brumback et al. ${ }^{44}$ This model incorporates study to study variability by assuming that defect rates among unexposed infants vary randomly according to a gamma distribution. $P$ values and confidence limits associated with the risk-ratio corresponding to CVS exposure can be computed using standard likelihood-based methods after integrating over the distribution of the random effects. We applied the method using parameter values that yielded prior means corresponding to the values observed in the historical series of 161,252 infants described earlier. Analyses were repeated under varying assumptions about the degree of study-to-study variability. The standard deviation was varied from being only one-quarter of the mean up to two times the mean. This ensured that the assumed prior distribution corresponded to the ranges of rates reported in the literature. For ex- 
Malformations Reported in CVS-Exposed Children

Table 1

Spectrum of reported malformations in CVS-exposed infants

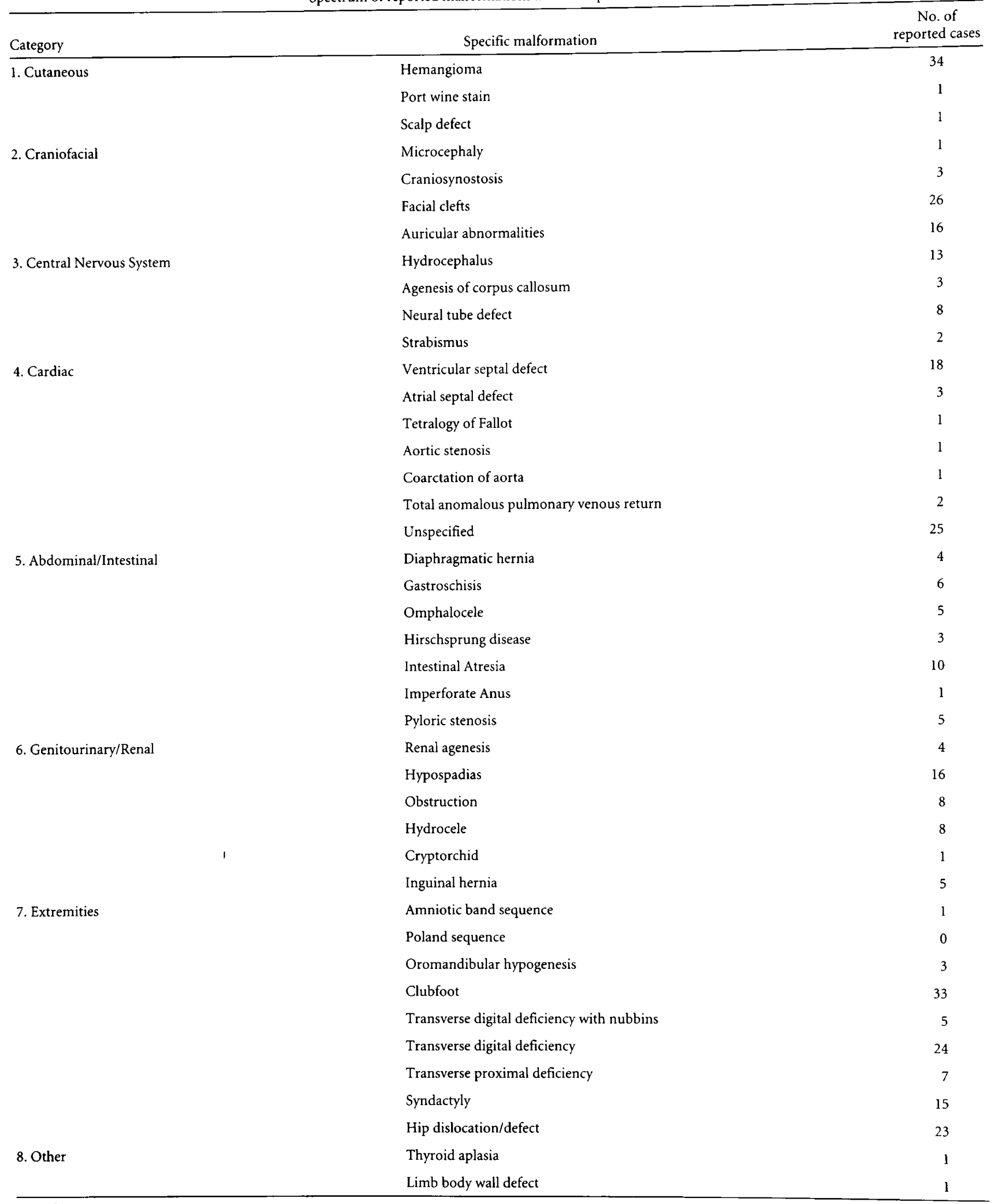

See references $16-40$. 
ample, intestinal atresia was observed at a rate of 0.062 per 1000 in our control series of 161,252 infants, whereas the rate reported in the literature is approximately 0.2 per 1000 . We, thus, chose a gamma prior with parameters 0.25 and 4.17 , which yielded a range of defect rates from 0.002 to 0.413 per 1000 . The $95 \%$ confidence interval on the log risk ratio associated with CVS exposure was $(1.1,3.45)$ with associated $p$ value of 0.001 (Table 2 ).

\section{RESULTS}

Information was available for 25,104 CVS-exposed pregnancies from the 25 studies. ${ }^{16-40}$ The frequencies of the following defects, thought to be secondary to vascular disruption, were calculated: cleft lip and/or cleft palate, club feet, intestinal atresia, gastroschisis, Poland anomaly, and amniotic band syndrome. For comparison, the frequency of two defects not at-

Table 2

Analysis of the frequency of the malformations using the poisson random effects model



*Analysis repeated with variable ranges assumed for the defect rate among unexposed.

**No published prevalence data available.

${ }^{* * *}$ Not of statistical significance (one-sided $p>0.05$ ). 
tributable to vascular disruption, diaphragmatic hernia and neural tube defects, was also calculated. These two were selected because they were reported commonly in the studies. The frequencies of terminal transverse limb deficiencies and oromandibular hypogenesis (OMLH), two types of limb defects reported to be associated with CVS, were also calculated. The frequencies of unilateral urethral obstruction sequence and renal agenesis could not be calculated accurately, because most cases did not distinguish between bilateral and unilateral cases. The frequencies of the CVS-associated malformations were compared with the frequency of the same malformations identified by the surveillance program at BWH in 161,252 nontransferred mothers and to published prevalence data (Tables 2 and 3$)$. Our analyses revealed significant $(p<0.05)$ associations between CVS and the occurrence of terminal transverse limb defects with nubbins, OMLH, gastroschisis, intestinal atresia, and club foot. No association was found with the presence of amniotic bands, Poland anomaly, diaphragmatic hernia, cleft lip/cleft palate, or neural tube defect.

Table 2 summarizes the analyses for the 10 different types of birth outcomes considered. The second column in the table shows the assumed mean rate per 1000 unexposed births used in our Poisson random effects model. Also shown is the range of values corresponding to the central $95 \%$ of the random effects distribution. For the purpose of a sensitivity analyses, each analysis was repeated three times using the same mean, but changing the assumed variability among unexposed births. For example, the first row (nubbins) reports an analysis based on an assumed prior mean of 0.056 per 1000 , but with three possible ranges. The first range $(0.001,0.206)$ is the one that allows the most variability and has the widest confidence interval for the true risk ratio associated with CVS exposure (Column 3 of Table 2). The fourth column of the table shows the $p$ value associated with the null hypothesis of no effect of CVS exposure. For the first 5 outcomes in Table 2, these $p$ values remain significant even when the prior distribution allows substantial variability in control rates. For the last five outcomes, the $p$ values all remain substantially $>0.05$, and the confidence intervals all contain 0 , regardless of the prior distribution assumed. The last column of the table shows the mean and ranges of control defect rates reported in the literature. In some cases (e.g., nubbins), no data are available from the literature. For outcomes, where such data are available, more confidence should be placed on prior distributions whose $95 \%$ ranges include those values.

More malformations were reported in the studies in which only the transabdominal method was used as compared with the transcervical method (Table 4). However, the number of total malformations reported was less than would be expected regardless of the method used ( $1 \%$ in the transcervical method studies, $1.6 \%$ in the transabdominal method studies, and $1 \%$ in studies using either method versus an expected baseline $2-3 \%) .43,45$ This may be a consequence of under-reporting of all the malformations.

Several studies reported on the timing of the CVS and the malformations seen (Table 5). No clear pattern between the malformations and the timing was noted.

\section{DISCUSSION}

The frequencies of gastroschisis, intestinal atresia, clubfoot, terminal transverse limb defects, and OMLH, defects postulated to be due to vascular disruption, were increased among the CVS-exposed infants in the published reports. However, other defects associated with vascular disruption, such as Poland syndrome, amniotic band syndrome, and cleft lip/cleft palate, were not increased. In addition, not all of the defects postulated to be due to vascular disruption were reported in

Table 3

Frequency of malformations

\begin{tabular}{lccc}
\hline Malformation & $\begin{array}{c}\text { CVS-exposed frequency } \\
\left(\text { rate/1000) }(\mathrm{n}=25,104)^{*}\right.\end{array}$ & $\begin{array}{c}\text { Published prevalence } \\
\text { data }(41,42)(\text { rate/1000) }\end{array}$ & $\begin{array}{c}\text { BWH* frequency (rate/ } \\
1000)(\mathrm{n}=161,252)\end{array}$ \\
\hline $\begin{array}{l}\text { Terminal transverse } \\
\text { Limb defects with nubbins }\end{array}$ & 0.20 & 0.76 & 0.056 \\
Amniotic bands & 0.04 & 0.03 & 0.093 \\
Poland anomaly & 0.0 & 0.05 & 0.031 \\
OMLH & 0.12 & 0.16 & 0.006 \\
Gastroschisis & 0.24 & 0.2 & 0.074 \\
Intestinal atresia & 0.40 & 1 & 0.062 \\
Clubfoot & 1.3 & 1 & 0.657 \\
Cleft lip/cleft palate & 1.0 & 0.18 & 0.657 \\
Diaphragmatic hernia & 0.16 & 1 & 0.062 \\
Neural tube defect & 0.32 & & 0.943 \\
\hline *Reported in the 25 articles & & & \\
\hline
\end{tabular}

${ }^{*}$ Reported in the 25 articles analyzed.

**Active Malformation Surveillance Program, Brigham and Women's Hospital, 1972-1974, 1979-1994.

${ }^{* * *}$ No prevalence data available that separates the transverse limb defects with nubbins from the rest of the transverse limb defects. 
Table 4

Route of CVS and reported malformations

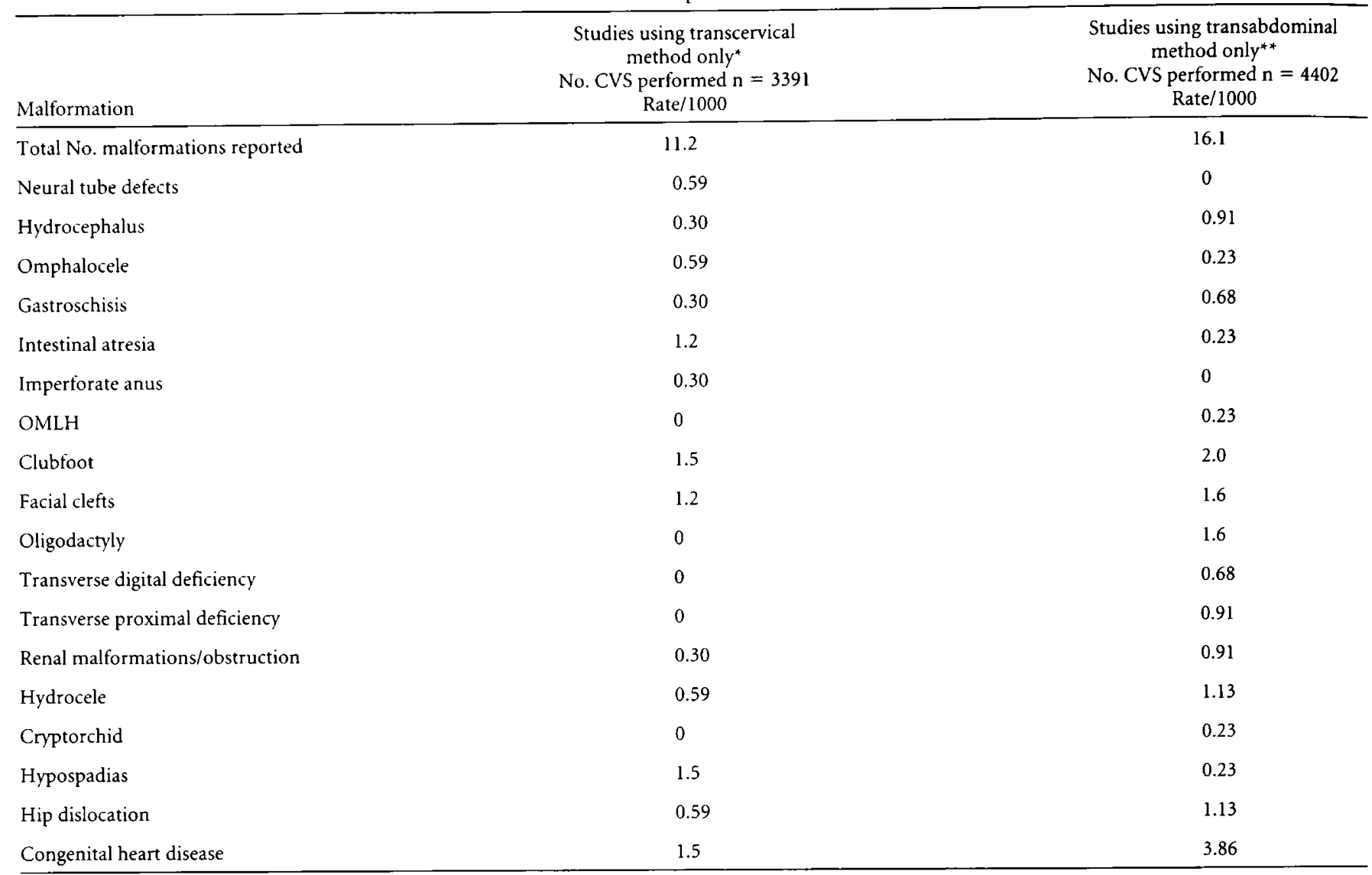

*Only studies in which only the transcervical method was used $(n=8)$.

** Only studies in which only the transabdominal method was used $(n=8)$.

these papers. For example, no cases of hemifacial microsomia, horse-shoe kidneys, porencephaly, or Klippel-Feil anomaly were reported in this series of reviewed articles.

There could be several reasons for these findings. First, there may have been under-reporting of defects in the reports. In fact, when the number of malformations reported was analyzed by the method used (Table 4) the malformation rate was lower than would have been expected. Furthermore, not all of the descriptions in the reports were as detailed as in others. In some of the reports, for example, the emphasis was on limb defects, and the other malformations identified were not described completely. ${ }^{29}$ This would result in an under-estimate of the defects in the CVS-exposed population. Second, in some studies, a number of the defects were lumped into one catego$\mathrm{ry},{ }^{35}$ such as facial clefts and did not distinguish between cleft palate alone and cleft lip \pm cleft palate, which may differ in their etiology. In our tabulation, we counted these as unspecified facial clefts. Third, malformations found in terminated fetuses were not included in every report. This would result in an under-estimation of the defects in the exposed population. Fourth, there was some variability in classification of the defects in the various studies. For example, amniotic band syndrome could be classified simply as a transverse limb defi- ciency. This would result in under-estimation of the frequency of amniotic band syndrome and over-estimation of transverse limb deficiency. Fifth, the diagnosis may be inaccurate. For example, a child with a limb defect could also have had a hypoplastic pectoralis muscle that was not detected and, therefore, would not have been classified as having Poland sequence. This would also result in a lower reported frequency of Poland sequence.

For some of the defects in question, the etiology may be heterogeneous, with vascular disruption being only one causative factor. In such cases it may be that there was not enough statistical power to detect an increase above the baseline. For example, cleft lip \pm cleft palate is a very diverse group with genetic heterogeneity and accordingly, it is not surprising that there was not a significant association with CVS.

The BWH database is very detailed, includes pregnancies terminated electively because of fetal abnormalities identified prenatally, and classifies defects precisely, using an extension of the ICD-9 codes. ${ }^{43}$ By having more precision in phenotype and the apparent etiology, affected infants with malformations due to apparent single mutant genes, chromosome abnormalities, and specific syndromes can be excluded or included as needed in establishing birth prevalence rates. Because the ex- 
Table 5

Timing of CVS procedure and reported malformations

\begin{tabular}{lcl}
\hline & $\begin{array}{c}\text { Gestational age (weeks) } \\
\text { at time of procedure } \\
\text { (range) }\end{array}$ & \multicolumn{1}{c}{ References } \\
\hline $\begin{array}{l}\text { Defect } \\
\quad \text { deficiency }\end{array}$ & $9-14$ & $25,27,29,34,40$ \\
$\begin{array}{l}\text { Proximal transverse limb } \\
\text { deficiency }\end{array}$ & 9.7 & 37 \\
$\begin{array}{l}\text { Oromandibular } \\
\text { hypogenesis }\end{array}$ & 8.4 & 34 \\
Intestinal atresia & $9-11.1$ & 25 \\
Gastroschisis & not reported & 0 \\
Poland anomaly & not reported & 0 \\
Clubfoot & $8-12.7$ & 25,27 \\
Facial clefts & $9.8-14$ & 25,37 \\
Syndactyly & $10-14.3$ & $21,25,27,34,37$ \\
Hydrocephalus & $9-12.7$ & $25,27,37$ \\
Neural tube defects & $9-9.5$ & 27,37 \\
Hemangioma & 10 & 27 \\
Diaphragmatic hernia & $9.9-14$ & 25,37 \\
Hypospadias & $9.3-11.9$ & 27,37 \\
Pyloric stenosis & $10.4-11$ & 25,27 \\
Congenital heart disease & $9-13$ & $25,27,37$ \\
\hline
\end{tabular}

amining pediatricians' findings in each newborn infants' record are reviewed, the ascertainment may be more complete than was the case for the data used in some of the 25 studies reviewed. This could result in higher prevalence rates in the BWH comparison group, which would decrease the probability of detecting an increase among CVS-exposed infants. Nevertheless, this makes the comparison more precise and less subject to errors caused by the lumping of similar, but etiologically different, malformations. The prevalence figures in the literature may lump malformations that are etiologically different together, resulting in higher frequencies.

All of the above limitations would result in an underestimation of the frequency of the various defects in the CVS-exposed population. Nonetheless, despite these limitations, this analysis has demonstrated that there was an increased frequency of three additional defects attributed to vascular disruption, intestinal atresia, gastroschisis, and clubfoot, among the CVSexposed infants. Complete data from a huge randomized trial would be the ideal way to address these limitations. In the absence of this, an analysis such as we have done, is the only way to address the present data.

\section{CONCLUSION}

Previous studies have reported that infants born from pregnancies in which the mother underwent chorionic villus sampling have an increased frequency of terminal transverse limb defects and cavernous hemangiomas. ${ }^{1,2,20}$ This review of 25 published reports of CVS-associated malformations suggested that these infants also have an increased frequency of intestinal atresia, gastroschisis, and clubfoot. The fact that an increased frequency of other defects attributed to vascular disruption was not seen could be due to under-ascertainment, misclassification, or 'lumping' of the defects identified in previous studies.

\section{References}

1. Firth HV, Boyd PA, Chamberlain P, MacKenzie IZ, Lindenbaum RH, Huson SM. Severe limb abnormalities after chorion villus sampling at 56-66 days' gestation. Lancet 1991;337:762-763.

2. Mastroiacovo P, Cavalcanti DP. Limb-reduction defects and chorion villus sampling. Lancet 1991;337:1091.

3. Van Allen MI, Hoyme HE, Jones KL. Vascular pathogenesis of limb defects. I. Radial artery anatomy in radial aplasia. J Pediatr 1982;101:832-838.

4. Hoyme HE. Jones KL, Van Allen MI, Saunders BS, Benirschke K. Vascular pathogenesis of transverse limb reduction defects. J Pediatr 1982;101:839-843.

5. Hoyme HE, Higginbottom MC, Jones KL. The vascular pathogenesis of gastroschisis: Intrauterine interruption of the omphalomesenteric artery. J Pediatr 1981;98: 228-231.

6. Louw IH. Jejunoileal atresia and stenosis. J Pediatr Surg 1966;1:8-23.

7. Poswillo $D$. The pathogenesis of the first and second branchial arch syndrome. Oral Surg 1973;35:302-328.

8. Bouwes Bavinck JN, Weaver DD. Subclavian artery supply disruption sequence: Hypothesis of a vascular etiology for Poland, Klippel-Feil and Moebius anomalies. Am J Med Genet 1986;23:903-918.

9. Johnson GF, Robinow M. Aglossia-Adactylia. Radiology 1978;128:127-132.

10. Van Allen MI. Structural anomalies resulting from vascular disruption. Pediatr Clin North Am 1992;39:255-277.

11. Eller KM, Kuller JA. Fetal porencephaly: A review of etiology, diagnosis and prognosis. Obstet Gynecol Surv 1995;50:684-687.

12. Hoyme HE, Higginbottom MC, Jones KL. Vascular etiology of disruptive structural defects in monozygotic twins. Pediatrics 1981;67:288-291.

13. Hoyme HE, Jones KL, Dixon SD, Jewett T, Hanson IW, Robinson LK, Msall ME, Allanson JE. Prenatal cocaine exposure and fetal vascular disruption. Pediatrics 1990;85:743-747.

14. Cragan JD. Teratogen update: Methylene blue. Teratology 1999;60:42-48.

15. Holmes LB. Report of National Institute of Child Health and Human Development Workshop on Chorionic Villus Sampling and Limb and Other Defects, October 20, 1992. Am J Obstet Gynecol 1993;169:1-6.

16. Ammala P, Hiilesmaa VK, Liukkonen S, Saisto T, Teramo K, Von Koskull H. Randomized trial comparing first-trimester transcervical chorionic villus sampling and second-trimester amniocentesis. Prenat Diagn 1993;13:919-927.

17. Borrell A, Costa D, Delgado RD, Fuster JJ, Soler A, Cararach J, Fortuny A. Transcervical chorionic villus sampling beyond 12 weeks of gestation. Ultrasound Obstet Gynecol 1996;7:416-420.

18. Brambati B, Lanzani A, Oldrini A. Transabdominal chorionic villus sampling. Clinical experience of 1159 cases. Prenat Diagn 1988;8:609-617.

19. Brambati B, Simoni G, Travi M, Danesino C, Tului L, Privitera O, Stioui S, Tedeschi S, Russo S, Primignani P. Genetic diagnosis by chorionic villus sampling before 8 gestational weeks: Efficiency, reliability, and risks on 317 completed pregnancies. Prenat Diagn 1992;12:789-799.

20. Burton BK, Schulz CJ, Burd LI. Spectrum of limb disruption defects associated with chorionic villus sampling. Pediatrics 1993;91:989-993.

21. Cederholm M, Axelsson O. A prospective comparative study on transabdominal chorionic villus sampling and amniocentesis performed at 10-13 weeks' gestation. Prenat Diagn 1997;17:311-317.

22. Crane JP, Beaver HA, Cheung SW. First trimester chorionic villus sampling versus mid-trimester genetic amniocentesis-preliminary results of a controlled prospective trial. Prenat Diagn 1988;8:355-366.

23. Donner C, Simon P, Karioun A, Delneste D, Abramowicz M, Cochaux P, Rodesch F. Experience with 1251 transcervical chorionic villus samplings performed in the first trimester by a single team of operators. Eur J Obstet Gynecol Reprod Biol 1995;60:4551.

24. Greenough A, Naik S, Yuksel B, Thompson PJ, Nicolaides KH. First-trimester invasive procedures and congenital abnormalities. Acta Paediatr 1997;86:1220-3.

25. Jahoda MG, Brandenburg H, Cohen-Overbeek T, Los FJ, Sachs ES, Wladimiroff JW. Terminal transverse limb defects and early chorionic villus sampling: Evaluation of 4300 cases with completed follow-up. Am J Med Genet 1993;46:483-485.

26. Kaplan P, Normandin J, Wilson GN, Plauchu H, Lippman A, Vekemans M. Mal- 


\section{Stoler et al.}

formations and minor anomalies in children whose mothers had prenatal diagnosis: Comparison between CVS and amniocentesis. Am J Med Genet 1990;37:366-370.

27. Mastroiacovo P, Tozzi AE, Agosti S, Bocchino G, Bovicelli L, Dalpra L, Carbone LD, Lituania M, Luttichau A, Mantegazza F, Nocera G, Pachi A, Passamonti U, Piombo G, Vasta AF. Transverse limb reduction defects after chorion villus sampling: A retrospective cohort study. GIDEF-Gruppo Italiano Diagnosi Embrio-Fetali. Prenat Diagn 1993;13:1051-1056.

28. Metaxotou C, Antsaklis A, Panagiotopoulou P, Benetou M, Mavrou A, Matsaniotis N. Prenatal diagnosis of chromosomal abnormalities from chorionic biopsy samples: Improved success rate using a modified direct method. Prenat Diagn 1987;7: 461-469.

29. Monni G, Ibba RM, Olla G, Rosatelli C, Cao A. Chorionic villus sampling by rigid forceps: Experience with 300 cases at risk for thalassemia major. Am J Obstet Gynecol 1987;156:912-914

30. Monni G, Ibba RM, Lai R, Giuseppina C, Silvia M, Olla G, Cao A. Transabdominal chorionic villus sampling: Fetal loss rate in relation to maternal and gestational age. Prenat Diagn 1992;12:815-820.

31. Ng NK, Liu DTY. Chorionic villus sampling. Evaluation of obstetric performance. Asia-Oceania J Obstet Gynecol 1992;18:31-35.

32. Nicolaides $\mathrm{KH}$, de Lourdes Brizot M, Patel F, Snijders R. Comparison of chorion villus sampling and early amniocentesis for karyotyping in 1492 singleton pregnancies. Fetal Diagn Ther 1996;11:9-15.

33. Palo $P$, Piiroinen $O$, Honkonen E, Lakkala $T$, Aula $P$. Transabdominal chorionic villus sampling and amniocentesis for prenatal diagnosis: 5 years' experience at a university centre. Prenat Diagn 1994;14:157-162.

34. Schloo R, Miny P, Holzgreve W, Horst J, Lenz W. Distal limb deficiency following chorionic villus sampling? Am J Med Genet 1992;42:404-413.

35. Shime J, Benzie R, Mohide P, Wilson D, Natale R, Johnson J Canadian multicenter randomized clinical trial of chorion villus sampling and amniocentesis. Surviving births. Prenat Diagn 1992;12:433-438.

36. Shulman LP, Elias S, Phillips OP, Grevengood C, Dungan JS, Simpson JL. Amniocentesis performed at 14 weeks' gestation or earlier: Comparison with first- trimester transabdominal chorionic villus sampling. Obstet Gynecol 1994;83:543-548.

37. Silver RK, MacGregor SN, Muhlbach LH, Knutel TA, Kambich MP. Congenital malformations subsequent to chorionic villus sampling: Outcome analysis of 1048 consecutive procedures. Prenat Diagn 1994;14:421-427.

38. Smidt-Jensen S, Permin M, Philip J, Lundsteen C, Zachary JM, Fowler SE, Grunin K. Randomized comparison of amniocentesis and transabdominal and transcervical chorionic villus sampling. Lancet 1992;340:1237-1244.

39. Wass DM, Brown GA, Warren PS, Saville TA. Completed follow-up of 1000 consecutive transcervical chorionic villus samplings performed by a single operator. Aust NZ J Obstet Gynaecol 1991;31:240-245.

40. Williams $\mathrm{J}$, Wang $\mathrm{BB}$, Rubin $\mathrm{CH}$, Aiken-Hunting $\mathrm{D}$. Chorionic villus sampling: Experience with 3016 cases performed by a single operator. Obstet Gynecol 1992;80: 1023-1029.

41. Buyse ML. Birth Defects Encyclopedia. Cambridge: Blackwell Scientific Publications, 1990 .

42. Calzolari E, Bianchi F, Dolk H, Milan M. Omphalocele and gastroschisis in Europe: A survey of 3 million births 1980-1990. EUROCAT Working Group. Am J Med Genet 1995;58:187-194.

43. Nelson K, Holmes LB. Malformations due to presumed spontaneous mutations in newborn infants. N Engl J Med 1989;320:19-23.

44. Brumback B, Ryan L, Holmes L. Adverse effects of CVS sampling: A meta analysis. Statistics Med 1999;18:2163-2175.

45. Lie RT, Wilcox AJ, Skjaerven R. A population-based study of the risk of recurrence of birth defects. N Engl J Med 1994;331:1-4. 